\title{
OS INVESTIMENTOS EM INFRAESTRUTURA NO BRASIL NO PERÍODO 1930-1990
}

\author{
Alexandre da Silva de Oliveira'
}

\section{Resumo}

O trabalho analisa os investimentos em infraestrutura entre 1930-1990. A hipótese é que a infraestrutura brasileira requer um Estado indutor do crescimento econômico de longo prazo. A justificativa é que os investimentos públicos, principalmente, do Plano de Metas e o II PND, ampliaram os investimentos em infraestrutura totais até os anos 1970, em contraposição, aos baixos níveis dos anos 1980-1990. Nesse sentido, o Estado tem o papel de coordenação e indução de investimentos que requerem grandes volumes de capitais altamente específicos, especialmente em infraestrutura. Assim, na seção 1 são apresentadas as principais questões teóricas. Na seção 2 são apresentadas as características dos ciclos de investimentos em infraestrutura dos anos 1930-1970. Na seção 3 é apresentada uma revisão das principais causas da crise dos anos 1980-1990 e os impactos sobre os investimentos em infraestrutura, seguida das conclusões do artigo.

Palavras-chave: Infraestrutura; Crescimento Econômico; Economia Brazileira

Classificação JEL: H54; O18

\section{APRESENTAÇÃO}

O trabalho apresenta as experiências de planejamento econômico no Brasil, com foco na investigação dos investimentos em infraestrutura no período de 1930-1990. O foco concentra-se na avaliação da hipótese de 
que o desenvolvimento da infraestrutura brasileira, por sua característica de monopólio natural, requer um Estado coordenador e indutor do crescimento econômico de longo prazo.

A justificativa é que os investimentos públicos, principalmente, do Plano de Metas e o II PND, ampliaram os investimentos privados nacionais e estrangeiros em infraestrutura até os anos 1970. Em contraposição, a carência de infraestrutura, em virtude da ausência estatal e da reestruturação produtiva dos anos 1980 e 1990.

O Estado tem um papel fundamental, por meio de sua atuação na promoção de uma maior taxa de crescimento dos investimentos. Os investimentos em infraestrutura ampliam mercados para suprir a grande demanda interna da população brasileira, por meio da oferta de níveis maiores de bens e serviços, sendo que provocam impactos sobre as estruturas de oferta destes, o que resulta em menores efeitos inflacionários.

Isto posto, na seção 1 é apresentado o debate teórico acerca dos determinantes do investimento e da poupança, que é o pano de fundo para a discussão sobre o planejamento e crescimento econômico. Na seção 2, são apresentadas as características dos ciclos de investimentos em infraestrutura dos anos 1930-1970, que caracterizam as experiências brasileiras de planejamento econômico, com destaque para o Plano de Metas e o II PND - Segundo Plano Nacional de Desenvolvimento.

Na seção 3 é apresentada uma revisão das condicionantes que determinaram a crise do Estado, desequilíbrios macroeconômicos e a escassez de investimentos públicos em infraestrutura no período de 1980-1990, seguida das conclusões do artigo.

\section{CRESCIMENTO, PLANEJAMENTO, REGULAÇÃO ECONÔ- MICA E INFRAESTRUTURA}

\subsection{A importância do crescimento e planejamento econômico para a infraestrutura}

A discussão acerca do fenômeno do crescimento econômico é antiga e deriva dos debates entre as abordagens ${ }^{2}$ keynesiana e ortodoxa, acerca do

Nessa seção, os principais referenciais bibliográficos foram: ARROUS (1999), BRUNO (2008), KALDOR (1974 e 1978), KEYNES (1988) e MARSHALL (1985). 
investimento e poupança. Na visão ortodoxa ${ }^{3}$, o crescimento econômico é um resultado de longo prazo e obtido com o aumento da poupança agregada. Nessa abordagem, utiliza-se o conceito de função de produção, com o produto (Y) sendo determinado pela acumulação de capital (K), a expansão do trabalho (L) e, com papel de destaque, da eficiência ou produtividade do trabalho (A):

$$
\mathrm{Yt}=f(\mathrm{Kt}, \mathrm{Lt}, \mathrm{At})
$$

A acumulação de capital (K) é representada pelo investimento bruto da economia, que é definido por $\left(\mathrm{I}_{\mathrm{b}}\right)$ e é determinado pela soma do acréscimo do estoque de capital da economia (Fbkf), que corresponde a ampliação da capacidade produtiva da economia e o termo (VarEst-dep), que representa as variações de estoque dos bens produzidos não vendidos, descontada a depreciação física do capital:

$$
\mathrm{I}_{\mathrm{b}}=\text { Fbkf }+(\text { VarEst-dep) }
$$

Na função de crescimento ortodoxa apresentada acima, temos que a taxa de crescimento do produto e da poupança são determinadas pela eficiência ou produtividade do trabalho (A), representada pela taxa de crescimento tecnológico, com o crescimento do produto sendo uma função crescente da razão entre capital e trabalho.

Nesse sentido, o papel da poupança é prover os recursos monetários necessários para a expansão de novo capital e a depreciação do capital já instalado. Se não ocorrem aumentos de eficiência ou produtividade do trabalho, não aumenta-se a poupança e, com isso, não ocorrem aumentos de investimentos e; portanto, não se viabiliza o crescimento crescimento econômico do país.

Em contrapartida a teoria ortodoxa, temos a abordagem alternativa de Keynes (1988), na qual o investimento é determinado previamente à poupança ${ }^{4}$, sendo que o produto interno bruto é definido pela igualdade entre rendas e despesas:

Conforme Simonsen e Cysne, os modelos ortodoxos de destaque são: modelo de Solow e o modelo de progresso técnico endógeno. (SIMONSEN; CYSNE, 2009, p. 534-542).

4 Na definição de Keynes, temos que: "Presumindo que as decisões de investir se tornem efetivas, é forçoso que elas restrinjam o consumo ou ampliem a renda. Assim sendo, nenhum ato de investimento, por si mesmo, pode deixar de determinar que o resíduo ou margem, a que chamamos de poupança, aumente numa quantidade equivalente". (KEYNES, 1988, p. 56). 
$\mathrm{R}=\mathrm{D}(\mathrm{I})$

A partir das teorias de Keynes, os países capitalistas se convenceram da necessidade da intervenção do governo para evitar ou reduzir os efeitos das crises cíclicas que caracterizam o modelo econômico capitalista. Essa atuação governamental se dá especialmente em benefício do emprego e dos investimentos, especialmente em infraestrutura.

Com isso, o planejamento econômico originou-se como um reconhecimento de que os mercados não são formas infalíveis na alocação de recursos nem, tampouco, ajustados automaticamente. Assim, é necessária uma atuação governamental ativa, por meio de políticas econômicas com o objetivo de ampliar os investimentos e aumentar o acesso da população aos serviços básicos, bem como, do ponto de vista produtivo, promover a redução dos estrangulamentos, com desdobramentos sobre o desenvolvimento econômico ${ }^{5}$.

Celso Furtado (1983 e 2001) define amplamente o planejamento econômico como o uso de técnicas e o estabelecimento de objetivos globais a serem alcançados pela economia em períodos previamente fixados. Referese, principalmente, à atividade governamental, com a formulação sistemática e a tomada de decisões de política econômica, com o objetivo de disciplinar a atividade produtiva para se promover o desenvolvimento econômico ${ }^{6}$.

Com isso, a função do Estado passou de um agente apenas participante da economia, para um papel de protagonista, provedor e impulsionador de políticas públicas no sentido de se atingir o desenvolvimento econômico. Para isso, assumiu funções como a estabilidade da moeda e o crédito, aumento da produção e distribuição de renda. Os Estados, por meio de seus governos institucionalizados passaram a atuar de forma direta e substituir atividades empresariais privadas para beneficiar a população, como na construção de estradas ou grandes obras de grande interesse público.

\footnotetext{
Nas palavras de Rodriguez (|98I), "admite-se que o livre jogo das forças do mercado conduz à persistente manifestação de problemas de balanço de pagamentos, de acumulação e subutilização de capital e de forças de trabalho (...) para que com a industrialização se consiga aumentar substancialmente os níveis de produtividade e otimizar a alocação de recursos, é preciso orientar-se por meio de uma política deliberada de desenvolvimento". (RODRIGUEZ, I981, p. 48).

6 Por outro lado, para Lafer, define-se como "uma visão ampla do desenvolvimento da economia, fixando objetivos a atingir e procurando assegurar a consistência entre a oferta e demanda de bens em todos os setores". (LAFER, 1970, p. 16).
} 
Sendo assim, a partir dos desdobramentos da crise econômica de 1929, a maioria dos países procurou adotar políticas de planejamento do econômico e industrialização, para se atingir o desenvolvimento. Já na década de 1930, o governo dos Estados Unidos interveio de forma acentuada no processo produtivo, com o New Deal do presidente Roosevelt, pode ser considerado uma das primeiras experiências no sentido de se realizar um planejamento econômico, com o objetivo de combater as consequências da terrível depressão que se seguiu à crise da bolsa de valores em 1929.

Gradativamente durante o século XX, os Estados passaram a serem produtores e reguladores de setores importantes para o novo ciclo de crescimento que se aproximava. Os Estados passaram a programar políticas em setores nos quais havia grandes dificuldades de viabilização de investimentos, como em infraestrutura há uma grande necessidade de volumosos capitais altamente específicos.

\subsection{A importância da regulação econômica para a infraestrutura}

Em sentido geral, para Bagnoli (2010), o termo regulação refere-se "às formas de organização da atividade econômica pelo Estado, tanto pela concessão de serviços públicos quanto pelo poder de polícia" (BAGNOLI, 2010, p. 84). É o conjunto de técnicas ou ações que, ao serem aplicadas a um processo, dispositivo, organização ou sistema, permite alcançar a estabilidade ou a conformidade de um objetivo previamente definido.

A abordagem mais difundida acerca da regulação é derivada tradição econômica ortodoxa, na qual a regulação é realizada pelo próprio mercado, por meio de mecanismos de preços e quantidades ofertas, segundo a lei da oferta e da procura ${ }^{7}$. Nesse sentido, há alguns mercados que existe uma maior eficiência econômica com apenas uma única empresa produzindo toda a quantidade ofertada no mercado, sendo chamados de monopólios naturais.

Segundo Carlton e Perloff (2000, p. 101-103), uma empresa é um monopólio natural, se ofertar bens e serviços a uma quantidade de mercado Q, abaixo do custo que existisse a oferta de duas ou mais empresas, Q1 e Q2,

Além da abordagem ortodoxa existe ainda a visão que advém da tradição geral da heterodoxia, na qual predomina a visão da Escola da regulação, cujas instituições, normas e mercados são os responsáveis pela regulação, com destaque para os schumpeterianos, os evolucionistas e os institucionalistas. Apesar da importância da temática, não são tratadas as divergências teóricas entre as abordagens ortodoxas e as heterodoxas. 
respectivamente, ou seja, cada empresa tem uma função de custo C(qk) e uma empresa pode produzir sozinha ao custo de $\mathrm{Q}$ menor do qua soma das empresas:

$$
\mathrm{C}(\mathrm{q})<\mathrm{C}(\mathrm{q} 1)+\mathrm{C}(\mathrm{q} 2)+\ldots+\mathrm{C}(\mathrm{qk})
$$

Sendo assim, a maneira menos custosa e mais eficiente de se produzir todas as unidades Q seria uma estrutura de mercado de forma de um monopólio natural, que inclui quedas dos custos médios e redução dos custos marginais.

Os setores de infraestrutura são reconhecidos como monopólios naturais, também pela situação de mercado em que os investimentos necessários são muitos elevados, e os custos marginais são muito baixos, dada a escala de produção, com bens exclusivos e com muito pouca ou nenhuma rivalidade como, por exemplo, nos setores de infraestrutura.

Segundo Randall (1987), quando a máxima eficiência econômica é alcançada por meio dos monopólios naturais, há uma necessidade de atuação governamental no sentido de evitar lucros excessivos por parte das empresas e adequar a quantidade e qualidade da oferta desses bens públicos. Então, a maior eficiência econômica promovida pelos monopólios naturais e a necessidade de se controlar lucros e oferta de bens públicos são as principais motivações por parte do Estado de regular alguns setores, como a infraestrutura.

A regulação é descrita como o arcabouço de mecanismos, constituído de leis, regimentos, decretos, portarias, que suportam o marco regulatório dotado de regras setoriais concernentes à tarifação e o ingresso de novas empresas no mercado ${ }^{8}$.

Ainda segundo Bagnoli (2010, p. 88-89), a regulação se materializa por meio das agências reguladoras, que são instituições criadas para se combater os abusos dos mercados concentrados, sendo um instrumento de resolução de conflitos e de preservação dos interesses públicos.

No que se refere à função destas agências reguladoras, Pires e Piccinini (1999), definem a atividade de regular, fiscalizar ou normatizar a prestação

\footnotetext{
Vilela e Maciel definem regulação por: "entende-se por regulação o estabelecimento de meios para exercer o controle social por meio de regras explicitadas em leis, decretos, concessões, contratos, decisões de órgãos reguladores, etc." (VILELA; MACIEL, 1999, p. 8). Outra definição é obtida em Pessini e Maciel, nas palavras "é apropriado afirmar que a regulação é a necessidade de permanente busca do equilíbrio entre a eficiência econômica e a equidade, por parte do Estado. (PESSINI; MACIEL, I995, p. 28I).
} 
dos serviços públicos, com imparcialidade diante de interesses do Estado, dos concessionários e dos usuários, com independência política, administrativa, financeira e funcional, com o objetivo de contribuir para atenuar a insegurança jurídica e os riscos políticos aos negócios privados de longo prazo. As agências reguladoras independentes e especializadas e a escolha de instrumentos que incentivem a eficiência produtiva e alocativa são consideradas requisitos de uma regulação eficiente.

De acordo com os autores (PIRES; PICCININI, 1999, p. 256), aquelas funções das agências reguladoras são operacionalizadas por meio dos seguintes instrumentos, que são: a) o controle de entrada e saída do mercado das empresas; b) controle de tarifárias para evitar práticas anticompetitivas e abuso do poder de mercado; c) promoção da competição, em setores nos quais o monopólio natural seja menos eficiente; d) aplicação de critérios tarifários que incentivem a eficiência produtiva e apropriação de ganhos aos consumidores; e e) fiscalização do cumprimento dos contratos de concessão.

No Brasil, estes instrumentos foram implementados, a partir dos anos 1990, caracterizando a atuação das agências reguladoras permitindo, principalmente, controlar as políticas de preços, regras de concorrência e a transparência de informações na prestação de serviços públicos nos setores de infraestrutura.

Houve regulamentação, por meio das leis no. 9.074/95 e a no. 8.987/95, com relação ao regime de concessão e permissão da prestação de serviços públicos. A qualidade desta regulação está associada ao conceito de segurança jurídica, definido pelos marcos regulatório 9 . A partir da regulamentação mencionada acima, a partir da década de 1990, iniciou-se a implantação de um marco regulatório capaz de incentivar maiores investimentos, reduções de preços e tarifas, como também a elevação da qualidade dos serviços.

No entanto, há ainda inúmeras incertezas regulatórias, associadas à fatores legais e burocráticos acerca de processos licitatórios, concessões de serviços públicos e as parcerias público-privadas, que inibem os investimentos privados, nacionais e estrangeiros, em infraestrutura ${ }^{10}$. Segundo

\footnotetext{
9 As agências são instituições técnicas, com independência política, criadas para arbitrar conflitos em contratos de concessão pública, sendo que um governo não pode desautorizar ou prostrar-se contra atos destes entes, sob risco de sinalizar aos agentes econômicos que os contratos podem sofrer alterações repentinas por motivações políticas.

${ }^{10} \mathrm{O}$ conceito de regulação estatal está associado à eficiência econômica, capaz de garantir a prestação de serviço público eficiente, com isonomia entre os agentes econômicos, Precisa ainda garantir segurança jurídica no ambiente interno de negócios, sinalizando para os agentes econômicos que, independentemente das transformações e
} 
Pires e Piccinini (1999), o maior desafio regulatório nos setores de infraestrutura refere-se à criação de um ambiente que, simultaneamente, estimule os investimentos privados, para a modernização e a expansão dos diversos segmentos, e promova o aumento do bem-estar do consumidor.

Segundo Rigolon (1996, p. 29), para todos os setores, é conveniente lembrar que apenas uma legislação abrangente e bem definida não é garantia de uma regulação eficiente da infraestrutura. O desenho de políticas de competição efetivas, a formulação da regulação e a imposição da legislação relevante não são tarefas triviais.

Como função típica do Estado, a regulação é mais bem executada se o poder público dispuser de recursos materiais suficientes e de pessoal qualificado. No Brasil, observou-se que a eficiência da regulação depende de uma ampla reforma do Estado, que compreenda não só o ajuste fiscal, mas também a estruturação de um serviço público eficiente ${ }^{11}$.

Nesse sentido, os setores de infraestrutura têm como principal característica a presença de elevados custos fixos, que se devem pelos investimentos altamente específicos de capital físico. Além disso, os custos fixos elevados destes setores provocam um duplo efeito: (i) maior eficiência produtiva é obtida somente por meio um estrutura concentrada de mercado, com altas barreiras à entrada e poucas empresas operadoras - monopólio natural; e (ii) problema de controle e fiscalização do superlucro de monopólio através de regulação adequada.

\section{AS EXPERIÊNCIAS BRASILEIRAS DE PLANEJAMENTO ECONÔMICO: OS CICLOS DE INVESTIMENTOS EM IN- FRAESTRUTURA ENTRE AS DÉCADAS DE 1930-1970}

No Brasil, o planejamento econômico e o Estado como indutor de crescimento de longo prazo resultaram em ampliação dos investimentos ${ }^{12}$

arbitragens que tenham de ocorrer serão feitas de forma a garantir as condições de rentabilidade dos negócios. Em comparação internacional, os marcos regulatórios eficiente, são consideradas vantagens comparativas em relação a outros países.

' Ainda segundo Rigolon, apenas uma regulação eficiente não é condição suficiente para o sucesso da reforma da infraestrutura. Outras variáveis, tais como a incerteza política, a estabilidade macroeconômica, a oferta de crédito para a infraestrutura, dentre outros.

12 Os principais autores são: FURTADO (200 I), LAFER ( 1970), LESSA (1 982), PIRES; GREMAUD ( 1999), PRADO (2002), TAVARES (1977). 
em infraestrutura foram características observadas no período de 1930-1970, que marca o início industrialização da economia brasileira.

A partir da crise econômica mundial de 1929, que desarticulou os setores agrário-exportadores, principalmente a cafeicultura, devido aos choques externos associados à demanda e os impactos sobre os preços dos preços de seus produtos, combinada a Revolução de 1930, criou-se as condições para a viabilização da transferência de poder para os capitalistas industriais (Furtado, 2001), como a transição do fator dinâmico da economia brasileira para o mercado interno ${ }^{13}$.

Esse processo foi estimulado, a partir de meados da década de 1930, por Getúlio Vargas, que adotou uma série de medidas, para impulsionar um processo de substituição de importações, com algumas restrições à sua expansão, provocada pela produção e da taxa de lucro produzida domesticamente. Com esse diagnóstico de insuficiência de capacidade de oferta, o Estado inicia um processo de criação de empresas estatais ${ }^{14}$ com foco em indústrias como de siderurgia, petróleo e derivados e mineração.

A partir de 1945, com o fim da segunda guerra mundial, os investimentos da economia brasileira foram impulsionados pela demanda doméstica. Segundo Bastos (2003), "o governo enveredou por um rumo, com controle de importações, expansão do crédito, plano de investimentos públicos, fomento à indústria substitutiva de importações, que provocou a oposição ideológica de técnicos e empresários prejudicados pela reversão da abertura, embora continuasse experimentando oposição política de lideranças, sobretudo Getúlio Vargas, sempre favoráveis à reversão da abertura". (BASTOS, 2003, p. 2).

Isto posto, a partir dos anos 1950, ocorreram iniciativas como a criação da Comissão Mista Brasil - Estados Unidos, para identificar e definir projetos de investimento em infraestrutura que seriam financiados pelo Eximbank norte-americano e pelo World Bank.

No que se refere ao projeto nacionalista de Vargas, houve a restrição do financiamento externo de projetos de infraestrutura na forma de investimentos diretos estrangeiros, sendo que Vargas estimulou estes projetos com altas

\footnotetext{
13 Segundo Prado Jr. a indústria ganha relevância para a economia brasileira nos pós- 1930, no enfrentamento dos efeitos da crise de 1929, sendo que o país "ingressa em numa fase em que a par do crescimento, sob certos aspectos, de suas forças produtivas e de diversificação de suas atividades econômicas - em particular no que diz respeito ao progresso industrial". (PRADO JR., 2002, p.30I).

14 Dentre outras medidas, foram criados o Conselho Nacional do Petróleo (1938), Companhia Siderúrgica Nacional ( 194I), Companhia Vale do Rio Doce ( 1943), Companhia Hidrelétrica do São Francisco (I945) e Petrobras ( 1953).
} 
taxas de lucro das atividades industriais aceleradas pela política de câmbio valorizado e de transferências de rendas dos setores agroexportadores para os setores industriais (REGO; MARQUES, 2001, p. 82).

Sendo assim, o período varguista foi um dos fundadores da infraestrutura que serviu de base ao inicio da industrialização brasileira com a contribuição significativa do capital estrangeiro ${ }^{15}$.

No Brasil, com o Plano SALTE (1947-1951), lançado pelo governo de Eurico Gaspar Dutra, com o objetivo de coordenar uma política para estimular investimentos nos setores de saúde, alimentação, transporte e energia, houve uam melhora nas condições de vida da população brasileira. A partir de 1952, foram realizados expressivos projetos de infraestrutura com apoio, do então criado Banco Nacional de Desenvolvimento Econômico (BNDE).

Já no governo de Juscelino Kubitschek (1956-1960), por meio do Conselho de Desenvolvimento, elaborou-se o Plano Quinquenal de Metas, cujos objetivos eram ampliar a participação do setor público na formação de capital, sendo caracterizado como um primeiro ciclo de investimentos públicos em setores de acumulação de capital no Brasil (Furtado, 1967 e 2007).

O Plano de Metas dividiu-se em 31 metas que privilegiavam cinco setores da economia brasileira priorizando os investimentos em: energia, transporte, indústrias de base, alimentação e educação e a meta-síntese, com a criação de Brasília. $\mathrm{O}$ plano teve tanto consequências positivas quanto negativas para o país, sendo que, por um lado, deu-se a modernização da indústria e; por outro, o forte endividamento internacional por causa de empréstimos, oriundos de importações de máquinas, equipamentos e instrumentos de produção ${ }^{16}$.

Apesar dos desequilíbrios macroeconômicos, observados nas contas públicas e os desajustes externos gerados, que culminou em um processo de hiperinflação e restrição ao crescimento, os investimentos do Plano de Metas impulsionaram um crescimento do PIB de 9,4\% ao ano, com papel de destaque para o Estado, que exerceu uma substancial demanda por in-

\footnotetext{
${ }^{15}$ A opção desenvolvimentista do governo era afirmada em quase todas as oportunidades no discurso presidencial. Não havia, entretanto, objeções maiores ao capital estrangeiro: a exemplo da implantação da grande siderurgia à época do Estado Novo, com capital e tecnologia estrangeiros, entendia-se que estes seriam bem-vindos ao país. (FONSECA; MONTEIRO, 2005, p. 222).

${ }^{16}$ Lessa identifica diversos "fatores objetivos" que sustentava o Plano de Metas. Um de seus eixos, os projetos de investimento em infraestrutura (...) destinava-se a equacionar notórias carências de uma industrialização desordenada com claros pontos de estrangulamento. (LESSA, 1982, p. 31-32).
} 
vestimento, de forma a sustentar a demanda efetiva e controlar o ciclo econômico. De acordo com Orenstein e Sochaczenski (1990), o financiamento dos investimentos do Plano de Metas era oriundo 50,0\% do governo, 35,0\% de fundos privados e $15,0 \%$ de agências públicas.

No que se refere ao financiamento dos investimentos, Lessa (1981) aponta que as componentes internas do plano foram as emissões de meios de pagamento e a concessão de crédito bancário. Com relação ao financiamento das estatais, especificamente no caso de infraestrutura, Ferreira e Malliagros (1998) afirmam que nos anos 1950, o BNDE foi o agente de financiamento mais importante. Já os capitais externos foram facilitados por políticas de capitais, que foram importantes para financiar a Formação Bruta de Capital Fixo.

Sobre os desdobramentos do Plano de Metas, Villela sintetiza que “entre 1956 e 1960, as principais metas de ampliação da produção e da infraestrutura econômica, reunidas no Plano de Metas, foram alcançadas, com o aumento da FBKF, bem como a meta-síntese de construção de Brasília. Nesse sentido, a política de desenvolvimento econômico de JK foi coroada de sucesso." (VILLELA, 2005, p. 64).

O Plano de Metas originou o emprego das técnicas de planejamento no país, com enfoque nos investimentos na indústria da transformação como uma característica do Estado Desenvolvimentista, sendo que esse aumento dos investimentos sinalizou a disposição do Estado em atuar não somente em setores tradicionais, como também na infraestrutura.

Outras experiências obtiveram um menor êxito, em comparação ao Plano de Metas. O Plano Trienal de Desenvolvimento Econômico e Social (1963-1965) tinha como objetivos fundamentais acelerar o crescimento do produto e uma melhor distribuição de renda. Já o Plano de Ação Econômica do Governo (PAEG), de 1964-1966, tinha o objetivo principal de eliminar os pontos de estrangulamentos internos da economia. No entanto, os desequilíbrios macroeconômicos internos, principalmente, o processo inflacionário e os desequilíbrios das contas externas e públicas, como também a crise de liquidez da economia internacional, diminuíram as possibilidades de obtenção de uma taxa de crescimento econômico consistente.

Nos anos 1970, os governos militares implantaram o Plano Nacional de Desenvolvimento Econômico, em duas fases, sendo a primeira chamada de I PND (1972-1974) e a segunda, o II PND (1975-1979), em meio a 
desequilíbrios macroeconômicos e restrições externas. Contudo, o II PND, instituído pelo governo do general Ernesto Geisel, obteve êxito, com o objetivo de ampliar o crescimento economico e corrigir desequilíbrios setoriais, principalmente em insumos básicos, bens de capital, alimentos e energia. $\mathrm{O}$ II PND foi uma forma de resposta à crise econômica originada no fim do chamado "milagre econômico brasileiro", período de seis anos consecutivos de crescimento a taxas superiores a $10,0 \%$ ao ano que, no entanto, criou uma série de desequilíbrios macroeconomicos, como desajustes fiscais, externos e inflacionários.

O plano foi viável politicamente, de acordo com Valadares da Silva $(2003)^{17}$, em virtude de uma aliança, principalmente, entre o capital financeiro nacional e as oligarquias tradicionais, que negociaram o papel do capital estrangeiro. O II PND se propôs a realizar um ajuste estrutural na economia brasileira, com alguns ajustes conjunturais de curto prazo, por meio da utilização instrumentos tais como taxa de câmbio, taxa básica de juros, regras para exportação e importação.

O plano obteve êxito parcial, sendo que, pela primeira vez na história, o Brasil conseguiu dominar todo o ciclo produtivo industrial. Contudo essa industrialização gerou uma dívida externa em expansão, culminando na moratória de 1982. O II PND exerceu um papel positivo para o ajustamento externo da economia brasileira e, principalmente, sustentar o crescimento econômico, impulsionado por meio de elevadas taxas de investimentos ${ }^{18}$.

Segundo Batista (1987), as metas do II PND associadas ao crescimento econômico passavam por uma ampliação da infraestrutura no país, com o objetivo de gerar maior emprego, renda e consumo, como também, atingir uma maior produtividade, competitividade e crescimento econômico. De fato, para este período, este processo não foi coordenado pelos mecanismos de ajustamento dos livres mercado, sendo necessária a articulação governamental.

\footnotetext{
7 "as diversas medidas e instrumentos foram criados para o fortalecimento à empresa nacional e que aparecem como reivindicações empresariais em relação às quais os empresários declararam-se atendidos. No entanto, a forte presença do capital estrangeiro nos setores mais dinâmicos dava um caráter contraditório ao discurso dos industriais". (VALADARES DA SILVA, 2003, p. 2I).

18 Gremaud e Pires apresentam as características do II PND: "Como resultado positivo do II PND não há como deixar de realçar o ajuste estrutural do balanço de pagamentos. Com a maturação dos grandes projetos do II PND, tornouse possível ao Brasil manter elevadas taxas de crescimento de seu produto sem que a economia resvalasse para o estrangulamento externo. Todavia, cabe notar que tal possibilidade viu-se comprometida pelo próprio padrão de financiamento do II PND." (GREMAUD; PIRES, 1999, p.96-97).
} 
O crescimento do PIB nos anos 1970 foi resultado da expansão da taxa anual de investimento, em média $24,0 \%$ do PIB entre 1974 e 1979, que possibilitou o crescimento de $6,8 \%$ ao ano, com ênfase nas indústrias básicas, notadamente nos setores de bens e capital, eletrônica pesada, insumos básicos, continuando o processo de substituição de importações.

A participação do setor público na FBKF foi a maior da história brasileira neste período, e a sustentação por anos consecutivos de altas taxas de crescimento e da FBKF/ PIB denota um processo de desenvolvimento. Estes efeitos dos investimentos e da sua alocação dependiam, conforme afirma Medeiros (2007), "de um regime monetário, cambial e fiscal favorecedor do alto crescimento". Entre 1950 e 1965, as variações da FBKF do setor público seguiam exatamente as variações da FBKF da administração pública, pois muitas empresas estatais estavam sendo criadas na época e ainda participavam pouco do total investido pelo governo federal, principalmente nos anos 1970 .

No período de 1930-1970 houve uma ampliação significativa da infraestrutura no Brasil que criou condições para o período de industrialização e superação da dependência externa das importações, que contribuiu em significativa medida os efeitos da dependência externa e intensificou o processo de substituição de importações ${ }^{19}$ - a relação FBKF / PIB atingiu $23,5 \%$, sendo que a relação dos investimentos em infraestrutura / PIB atingiu 5,4\% do PIB (Anexo 1). Foi expressiva a importância do Estado, por meio dos investimentos públicos, que impulsionou os investimentos privados, nacionais e estrangeiros, ampliando a infraestrutura brasileira, com destaque para o papel das empresas estatais.

No entanto, esse processo causou efeitos colaterais na economia brasileira, com a elevada participação de empréstimos externos, que aumentou a dívida externa, a escalada da taxa de inflação e a crise fiscal do país.

\section{CRISE DO ESTADO, DESEQUILÍBRIOS MACROECONÔMI- COS E A ESCASSEZ DE INVESTIMENTOS PÚBLICOS EM IN- FRAESTRUTURA: NOTAS SOBRE AS DÉCADAS DE 1980-1990}

Nos anos 1980-1990, houve a crise do Estado, desequilíbrios macroeconômicos, o que resultou em uma escassez de investimentos públicos em

19 Ver principalmente em TAVARES ( 1977), CASTRO; SOUZA ( I 985) e FURTADO (200 I). 
infraestrutura. As privatizações redefiniram o papel dos investimentos no país e não foram capazes de impulsionar os investimentos necessários para um crescimento da economia brasileira.

Os anos 1980 são caracterizados como um período de crise do Estado brasileiro, com desequilíbrios macroeconômicos, com destaque para a deterioração da situação das contas públicas e externas e a ascensão da inflação, em um contexto de cenário externo de restrição financeira. Estas condicionantes provocaram instabilidade do crescimento econômico do país (BAER, 2004, p. 167).

Com a implantação do Plano Cruzado entre 1985-86, houve uma tentativa por parte do governo de estabilizar a taxa de inflação, com medidas basicamente de controle de preços. Apesar do sucesso inicial do Plano Cruzado, a economia brasileira retornou a uma situação critica de variabilidade da taxa de crescimento do PIB, com uma elevação da taxa de desemprego e a volta das elevadas taxas de inflação.

No mandato do presidente José Sarney (1985-1990), houve uma recuperação do crescimento do PIB, mesmo com a implementação de estabilização e pacotes fiscais para combater as crises internas e externas. Porém, houve uma queda da FBKF e investimentos em infraestrutura dos anos 1970 para os anos 1980 - de $23,5 \%$ para $22,2 \%$ da relação FBKF / PIB e de 5,4\% para $3,6 \%$ da relação dos investimentos em infraestrutura / PIB atingiu 5,4\% do PIB (Anexo 1). Com isso, houve queda de produtividade e eficiência, tornando a infraestrutura do País obsoleta e incapaz de proporcionar condições de crescimento econômico acelerado, além dos amplos impactos sobre a competitividade da economia brasileira.

O regime macroeconômico adotado pelo Brasil estava em sintonia com as tendências neoliberais impostas sobre os países periféricos, que também beneficiavam a elite financeira, núcleo do grupo de interesses em ascensão no poder. A intensificação da integração entre os mercados financeiros e de produtos implicou em menor autonomia das políticas econômicas nacionais, assim como sobre os seus efeitos, tanto domésticos como globais. $\mathrm{O}$ início da abertura e desregulamentação dos mercados brasileiros amplificou a perda de autonomia das políticas econômicas locais, em detrimento ao aumento de influência de fatores externos, com uma maior volatilidade nos mercados financeiros e de capitais. 
Os anos 1980 foram marcados pela atrofia dos investimentos estatais e o agravamento das incertezas regulatórias e, principalmente, dos fundamentos macroeconômicos. Com isso, não se promoveu um ambiente favorável aos investimentos privados, nacionais e estrangeiros, com o impacto sobre a infraestrutura brasileira.

Após dois choques de preços internacionais do petróleo (1973 e 1979) e a crise financeira do México (1982), os principais credores internacionais, ao perceberem as dificuldades dos países em desenvolvimento em conduzir uma dívida bastante elevada e os novos financiamentos, o que provocou o aumento das exigências para a obtenção de novos empréstimos. Houve, como consequência, maior monitoramento por parte de instituições como o International Monetary Fund (IMF) para a obtenção de ajustes internos das economias em desenvolvimento e garantia de pagamento dos juros.

Restabelecida a normalidade institucional, o governo José Sarney implantou, em 1986, o Plano de Estabilização Econômica, conhecido como plano Cruzado, nome da nova moeda então criada, que substituiu o cruzeiro. Seu objetivo principal foi o combate à inflação, e para tanto se estabeleceu a nova moeda, com medidas relacionadas ao congelamento de preços e salários e a eliminação das indexações de preços e salários. As medidas desestimularam a formação de poupança interna e o consumo. Com o congelamento da taxa de câmbio, as exportações caíram e as importações aumentaram. Já no plano Cruzado II de 1987, ocorreu o descongelamento de preços e a alteração dos critérios do cálculo da inflação, no entanto, sem o sucesso pretendido, sendo que até 1989, o governo Sarney implantou dois planos de reforma da economia.

O primeiro foi Plano de Controle Macroeconômico, também chamado de Plano Bresser, de 1987, que congelou preços, salários e aluguéis por noventa dias e adiou a realização de grandes obras públicas. O segundo foi o Plano Verão de 1989, que instituiu o cruzado novo como moeda nacional e extinguiu a política de correção monetária, sendo que este plano não obteve êxito no que se refere ao controle de inflação, como os demais planos econômicos heterodoxos.

Com a inflação em torno de $80 \%$ ao mês, governo de Fernando Collor de Melo, implantou o Plano Brasil Novo, ou o Plano Collor, a partir de 1990, para evitar a hiperinflação e promover o ajuste da economia. O plano 
congelou preços e salários, aumentou impostos e tarifas, instituiu novos tributos e anunciou o programa de privatização de empresas estatais.

Com as sucessivas dificuldades no enfrentamento da questão da inflação, a partir de 1994, o governo implantou o plano Real, que, ao contrário dos anteriores, não congelou preços e salários ou choques na economia, com características ortodoxas. Para isso, concentrou-se basicamente no combate ao desequilíbrio das contas públicas, principal causa da inflação na opinião de muitos analistas.

No entanto, com a estabilização da moeda e dos fundamentos macroeconômicos, restringiu as condições de viabilização dos investimentos em infraestrutura suficiente para um novo ciclo de investimentos em infraestrutura no país.

Os processos de globalização, associados às estratégias das empresas multinacionais e de regionalização, vinculado à formação de blocos econômicos provocaram alguns impactos para os países em desenvolvimento, especialmente para o Brasil, com desdobramentos acerca das condições de privatização dos setores de infraestrutura no Brasil.

Apesar das evidências no que se referem à nova fase da acumulação capitalista predominante a partir das últimas duas décadas do século XX, há quem questione as evidências de que estaria havendo uma globalização da economia, uma vez que se observa uma crescente concentração nas decisões e nas desigualdades entre os países.

A globalização da economia internacional e a internacionalização da produção das empresas multinacionais ampliaram o comércio e as transferências de tecnologia globalmente, com o impulso dos desenvolvimentos dos mercados financeiros e de capitais, cada vez mais liberalizados e desregulamentados.

A globalização representou em alguns casos a perda de autonomia de política econômica. Na verdade, a autonomia das políticas econômicas dos países fica limitada quando estes fazem uso de política de estabilização, excessivamente baseada na liberalização do mercado e da fixação de metas monetárias, que causam impactos importantes tanto na política monetária como nos juros.

Apesar da maior relevância das empresas no cenário da globalização, os Estados nacionais ainda desempenham um importante papel no posiciona- 
mento estratégico dos países ${ }^{20}$. As mudanças provocadas pelos investimentos diretos estrangeiros alteraram os padrões de estruturas produtivo-organizacionais e redefiniram a noção de competitividade internacional, com a crescente necessidade de investimentos público e privados de longo prazo como, por exemplo, nos setores de infraestrutura.

Com a adoção do Plano Real em 1994, cumpriram-se as etapas para a estabilidade da moeda. No entanto, as desigualdades sociais continuaram excessivas, com o empobrecimento de vastas parcelas da população e queda relativa do mercado de trabalho, que crescia em ritmo menor do que o aumento da população.

A inserção externa economia brasileira nos anos $1990^{21}$ significou, por um lado, uma forte reestruturação da produção, tendo como pano de fundo o novo paradigma industrial, baseado nas mudanças provocadas pela globalização, a abertura da economia, a privatização e a desregulamentação, e por outro, causou uma desaceleração do crescimento e acumulação de capital no país.

Nesse sentido, a queda dos investimentos em infraestrutura e a precariedade dos serviços públicos, revelam um fator poderoso limitando as perspectivas de crescimento da economia brasileira, principalmente nos anos 1990. Sendo assim, se esta tendência não for revertida no longo prazo, deve ocorrer uma restrição à taxa de crescimento do produto e da produtividade da economia, devido aos baixos investimentos públicos.

O fenômeno das privatizações de empresas e serviços não significa um Estado mínimo para Franco (1999) ou Moreira e Giambiagi (2000). Para esses autores, a lógica é deixar governos e empreendedores privados fazerem o que sabem fazer melhor, sendo que um Estado grande requer muitos impostos para custear muitas despesas com muitas atividades. Já um Estado menor, atento somente aos serviços sociais principais, requer menos imposto, para arcar com menos despesas, fruto de menos atividades.

\footnotetext{
20 Adicionalmente, fatores de ordem política, como o grau de intervenção do Estado, também foram relevantes. Os casos de sucesso estiveram associados, na maioria das situações, à capacidade de articulação entre as condições microeconômicas de organização industrial e às políticas do Estado.

21 "o objetivo das reformas que estavam na pauta de discussão, no Brasil, na entrada dos anos 1990, não deveria ser, portanto, a destruição das instituições que mobilizaram recursos financeiros e poupanças ou a ruína dos agentes produtivos superavitários, mas sim estancar o conteúdo especulativo que suas ações apresentavam, recuperar suas funções e a contribuição deles esperada na formação do emprego e do produto nacional." (BELLUZZO; ALMEIDA, 2002, p. 282).
} 
A questão da privatização foi um dos aspectos mais polêmicos da década de 1990. Com a criação do Programa Nacional de Desestatização (PND) em 1990, tornando-se assim, uma parte integrante das reformas econômicas do governo. No período 1991-1998, somente no âmbito federal, cerca de 60 empresas públicas foram privatizadas, gerando um resultado de cerca de US\$ 28,49 bilhões no período.

O Banco Nacional de Desenvolvimento Econômico e Social (BNDES) representou um importante papel para o PND, pois foi designado como gestor do Fundo Nacional de Desestatização (FND). Suas principais atribuições estavam relacionadas à licitação, contratação, coordenação e supervisão das operações de venda das empresas públicas ao capital privado. O Banco teve o papel ainda de prover recursos, como alternativa de investimento para a infraestrutura diante da falta de recursos orçamentários. No que se referem aos estados, estes aderiram ao programa, com a venda de empresas públicas e o leilão de concessões, atraindo investidores privados para construir uma nova infraestrutura ${ }^{22}$.

Com a evolução das privatizações, houve a necessidade crescente, por parte dos governos, na esfera federal, estadual e municipal, de atrair investimentos privados para atender as demandas e os anseios crescentes da população diante da insuficiência de recursos nos orçamentos públicos, comprometidos quase totalmente com despesas como aposentadorias, quadro de funcionários públicos, saúde pública, segurança, educação e pagamento de juros de dívidas já contraídas ${ }^{23}$.

De um lado, o processo de abertura e as privatizações foram realizados sem coordenação ou objetivos predefinidos. Por outro lado, a participação do capital estrangeiro, impulsionou a produtividade da infraestrutura, principalmente do setor de telecomunicações. Apesar disso, a queda da FBKF

${ }^{22}$ Rigolon explica as externalidades positivas oriundas dos investimentos em infraestrutura: "Estimular o investimento em infraestrutura pode ser uma estratégia eficiente para promover o investimento privado e a retomada do crescimento econômico sustentado. Por outro lado, dadas externalidades associadas à oferta de serviços de infraestrutura, há uma tendência de o investimento privado nesse setor ser inferior ao socialmente ótimo". (RIGOLON, I998, p. I 48).

23 Pinheiro, Giambiagi e Moreira apontam que "na área da infraestrutura a privatização representa apenas uma etapa das reformas na regulamentação. No caso da infraestrutura, existem necessidades maiores do que a mera redução das perdas técnicas. É preciso avançar mais adiante: aperfeiçoar a gestão e recuperar as instalações existentes para poder acomodar a expansão da capacidade e para traduzir os ganhos de produtividade em preços mais baixos para o consumidor. Nessas áreas, o grau de sucesso obtido pela nova estrutura regulamentadora é bastante heterogêneo, o que reflete as diferenças qualitativas da regulamentação dos diferentes setores." (PINHEIRO; GIAMBIAGI; MOREIRA, 200I, p. 13). 
e dos investimentos em infraestrutura nos anos 1990, em comparação aos anos 1970 foi pronunciada - de 23,5\% para 18,2\% da relação FBKF / PIB e de $5,4 \%$ para $2,3 \%$ da relação dos investimentos em infraestrutura / PIB atingiu 5,4\% do PIB (Anexo 1), com amplos impactos negativos sobre as condições de crescimento econômico de longo prazo da economia brasileira.

Fatores como os desequilíbrios macroeconômicos, amplificados pela crise da dívida externa da década de 1980, hiperinflação e desajustes das contas públicas provocaram uma queda significativa dos investimentos públicos em infraestrutura no período. Estes mesmos fatores negativos, como também o período de incertezas políticas associadas à transição da ditadura para a democracia, bem como excessiva burocracia e inseguranças institucionais, provocaram expectativas negativas, fazendo com que os investimentos privados também recuassem.

\section{CONCLUSÕES}

O trabalho apresentou as experiências de planejamento econômico no Brasil, com foco na investigação dos investimentos em infraestrutura no período de 1930-1990. Constatou-se que os investimentos públicos, principalmente, do Plano de Metas e o II PND, ampliaram os investimentos privados nacionais e estrangeiros em infraestrutura até os anos 1970, em contraposição a carência de infraestrutura, em virtude da ausência estatal e da reestruturação produtiva dos anos 1980 e 1990.

Com relação ao papel do Estado, a partir das teorias de Keynes, os países capitalistas se convenceram da necessidade da intervenção do governo para evitar ou reduzir os efeitos das crises cíclicas que caracterizam o modelo econômico capitalista, sendo que a atuação estatal se dá especialmente em benefício do emprego e dos investimentos.

A respeito da função de regulação estatal, observou-se que a eficiência da regulação depende de uma ampla reforma do Estado, que compreenda não só o ajuste fiscal, mas também a estruturação de um serviço público eficiente.

Foi apresentado o período de 1930-1970, no qual houve uma ampliação significativa da infraestrutura no Brasil que criou condições para o período de industrialização e superação da dependência externa das importações, 
que contribuiu em significativa medida os efeitos da dependência externa e intensificou o processo de substituição de importações. Este é um resultado do expressivo papel do Estado, por meio dos investimentos públicos, que impulsionou os investimentos privados, nacionais e estrangeiros, ampliando a infraestrutura brasileira, com destaque para o papel das empresas estatais.

Já os anos 1980 foram marcados pela atrofia dos investimentos estatais e o agravamento das incertezas regulatórias e, principalmente, dos fundamentos macroeconômicos. Com isso, não se promoveu um ambiente favorável aos investimentos privados, nacionais e estrangeiros, com o impacto sobre a infraestrutura brasileira.

Os anos 1990 foram marcados pela continuidade da atrofia dos investimentos estatais e o aprofundamento do processo de privatizações. Em setores como de telecomunicações, observa-se uma modernização e ampliação da oferta; contrariamente, em setores como de energia elétrica, houve uma paralisação dos investimentos, em virtude das incertezas regulatórias e a ausência do Estado.

Constatou-se que, há uma grande dificuldade de viabilização doméstica dos investimentos necessários, principalmente por que, os investimentos em infraestrutura têm como característica a necessidade de grandes volumes de capitais altamente específicos.

Para se viabilizar estes investimentos, é preciso que haja um bom desenho regulatório, para se reduzir as incertezas de longo prazo, como também políticas microeconômicas devem ser voltadas para os objetivos estratégicos do país no longo prazo - direcionando os investimentos domésticos e externos no sentido da promoção do bem estar social e aumento da produtividade e competitividade da economia nacional.

Com a formulação sistemática e a tomada de decisões de política econômica, tem o papel de disciplinar a atividade produtiva e promover o crescimento econômico, por meio de investimentos em infraestrutura. Nos setores de infraestrutura, caracterizados como monopólios naturais, há uma necessidade de atuação governamental no sentido de evitar lucros excessivos por parte das empresas e adequar a quantidade e qualidade da oferta desses bens públicos. Nesse sentido, o planejamento econômico, com o uso de técnicas e o estabelecimento de objetivos globais a serem alcançados pela economia em períodos previamente fixados exerce papel importante. 


\section{THE INFRASTRUCTURE INVESTMENTS IN BRAZIL DURING THE PERIOD 1930-1990.}

\section{Abstract}

The paper analysis infrastructure investments during 1930-1990. The hypothesis is that the infrastructure development in Brazil requires a State inducing long-term economic growth. The rationale is that public investments, mainly of Plano de Metas and II PND, increased the total infrastructure investments until the 1970s, in contrast to the low level of 1980-1990s. In this sense, the State has a coordinating and induction role on investments with required large volumes and highly specific capitals, especially in infrastructure. That is, Section 1 presents the main theoretical issues. Section 2 presents the features of the infrastructure investments cycles of 1930-1970. Section 3 presents a review of the main causes 1980-1990 crisis and the impacts on infrastructure, followed by paper conclusions.

Keywords: Infrastructure; Economic Growth; Brazilian Economy

\section{JEL Classification: H54; O18}

\section{REFERÊNCIAS}

ASSOCIAÇÃO BRASILEIRA DA INFRAESTRUTURA E INDÚSTRIA DE BASE (ABDIB). Publicações. Dsponível em: < http://www.abdib.org. br/index/conjuntura_infraestrutura_capa.cfm?id_edicao $=0>$. Acessado em 22.12.2011.

ARROUS, J. Les théories de la croissance. Éditions du Seuil, février, 1999.

ASSOCIAÇÃO KEYNESIANA BRASILEIRA (AKB). Dossiê da Crise II. Disponível em: $<$ http://www.ppge.ufrgs.br/akb>. Acessado em 03.12.2010. 
BAER, W. A economia brasileira. Editora Nobel, 2a . Edição. São Paulo, 2004.

BAGNOLI, V. Direito econômico. $4^{\mathrm{a}}$. Ed. - série leituras jurídicas: provas e concursos; v. 29. São Paulo: Atlas, 2010.

BASTOS, P. Desenvolvimentismo incoerente? Comentários sobre o projeto do segundo governo Vargas e as ideais econômicas de Horário Lafer (19481952). In: XXXIII Encontro Nacional de Economia da ANPEC. Natal, 2005.

. O presidente desiludido: pêndulo de política econômica no governo Dutra (1946-1951). In: V Congresso Brasileiro de História Econômica. ABPHE, 5, 2003, Caxambu.

\section{BANCO NACIONAL DE DESENVOLVIMENTO ECONÔMICO E SO- CIAL (BNDES)}

Portal de Estatísticas. Disponível em: $<$ http://www.bndes.gov.br $>$. Acessado em 02.12.2010.

BATISTA, J. A estratégia de ajustamento externo do Segundo Plano Nacional de Desenvolvimento. Revista de Economia Política, vol. 7, no. 2, abril-junho de 1987.

BELlUZZO, L.; ALMEIDA, J. Depois da Queda. Rio de Janeiro: Civilização Brasileira, 2002.

BIELSCHOWSKY, R. O pensamento econômico brasileiro: o ciclo ideológico do desenvolvimentismo - 1930-1964. Editora Contraponto. 2000.

. (Coord.) Investimento e reformas no Brasil. Indústria e infra-estrutura nos anos 1990. Brasília: IPEA/CEPAL. Escritório no Brasil, 2002. Disponível em: <http://www.eclac.cl/publicaciones/xml/4/11754/ investimentoereformasnobrasil.pdf $>$. Acessado em 23.02.2011.

BRUNO, M. Acumulação de capital, distribuição e crescimento econômico no Brasil: uma análise dos determinantes de longo prazo. IPEA. Texto para Discussão no. 1364. Rio de Janeiro, novembro de 2008. 
CARLTON, D; PERLOFF, J. Modern industrial organization. Third edition. Addison-Wesley: New York, 2000.

CARDOSO DE MELLO, J. O capitalismo tardio. Editora Brasiliense. São Paulo, 1982.

CASTRO. A.; SOUZA, F. A economia brasileira em marcha forçada. Editora Paz e Terra, 1985.

CHANG, H. Rethinking Development Economics. London, Antherm Press, 2002.

FERREIRA, P. Investimento em infraestrutura no Brasil: fatos estilizados e relações de logo prazo. IPEA. Pesquisa e Planejamento Econômico, v. 26, n. 2, ago. 1996, p. 231-252.

.; MALLIAGROS, T. Investimentos, fontes de financiamento e evolução do setor de infraestrutura no Brasil: 1950-1996. Rio de Janeiro: Ensaios Econômicos. no. 346, Fundação Getúlio Vargas, maio/1999. Disponível em: <http://virtualbib.fgv.br/dspace/bitstream/handle/10438/575/1199. pdf?sequence $=2>$. Acessado em 03.02.2011.

FILGUEIRAS, L. História do Plano Real. São Paulo, Editora Boitempo, 2001.

FONSECA, P.; MONTEIRO, S. Credibilidade e Populismo no Brasil: a política econômica dos governos Vargas e Goulart. Revista Brasileira de Economia. Rio de Janeiro 59(2):215-243 Abril/Junho/2005.

FRANCO, G. O Desafio Brasileiro - Ensaios sobre Desenvolvimento, Globalização e Moeda. Editora 34, Rio de Janeiro, 1999.

FURTADO, C. Formação econômica do Brasil. 30ª ed. São Paulo: Companhia das Letras, 2001. 
. Teoria e política do desenvolvimento econômico, Editora Abril, São Paulo, 1983.

GARCIA, M. O financiamento à infra-estrutura e a retomada do crescimento econômico sustentado. Revista de Economia Política, vol. 16, no. 3 (63), julho-setembro/1996.

GREMAUD, A.; PIRES, J. II Plano Nacional de Desenvolvimento - II PND (1975-1979). In. Planejamento no Brasil II. KON, A. Editora Perspectiva, São Paulo, 1999.

INSTITUTO BRASILEIRO DE GEOGRAGIA E ESTATÍSTICA(IBGE). Portal de Estatísticas. Disponível em: $<$ http://www.ibge.gov.br $>$. Acessado em 05.04.2009.

INSTITUTO DE ESTUDOS PARA O DESENVOLVIMENTO INDUSTRIAL (IEDI). Carta IEDI no. 436. Publicada em 08.10.2010. Disponível em: <http://www.iedi.org.br/>.

INSTITUTO DE PESQUISA ECONÔMICA APLICADA (IPEA). Portal de Estatísticas. Disponível em: <http://www.ipeadata.gov.br>. Acessado em 05.12.2010.

INTERNATIONAL MONETARY FUND (IMF). Portal de Estatísticas. Disponível em: < http://www.imf.org/external/data.htm>.

KALDOR, N. Capital accumulation and economic growth. 1961. Apud Acumulation du Capital et Croissance Economic. Abraham Frois, 1974.

. Collect Economic Essays 5: further essays on economic theory. Duckworth, 1978, p. 7-29.

KEYNES, J. A teoria geral do emprego, do juro e da moeda. Editora Nova Cultural. São Paulo, 1988.

LAFER, B. Planejamento no Brasil. Editora Perspectiva, São Paulo, 1970. 
LESSA, C. Quinze anos de política econômica. São Paulo. Editora Brasiliense, 1982.

MACARINI, J. A política econômica da ditadura militar no limiar do "milagre" brasileiro: 1967/69. Texto para discussão. IE/UNICAMP, n. 99, set. 2000.

MARSHALL, A. Princípios de economia. Nova Cultural. Vol.I e II. 1985.

MEDEIROS, C. Regime macroeconômico, crescimento e inovações no Brasil. (mimeo). 2007.

MOREIRA, M.(Org.). A Economia brasileira nos anos 90. Rio de Janeiro: BNDES, 1999.

. A indústria brasileira nos anos 90: o que já se pode dizer. In: GIAMBIAGI, F.; MOREIRA, M. (Org.). A Economia brasileira nos anos 90. Rio de Janeiro: BNDES, 1999.

; CORREA, P. Abertura comercial e indústria: o que se pode esperar e o que se vem obtendo. Revista de Economia Política, v. 17, n. 2 (66), abr.jun., 1997. Disponível em: <http://geein.fclar.unesp.br/reunioes/ quarta/arquivos $>$. Acessado em 20.12.2009.

ORENSTEIN, L.; SOCHACZENSKI, A. Democracia com desenvolvimento: 1956-1961. In. ABREU, M. (Org.) A Ordem do Progresso. Rio de Janeiro: Editora Campus. 1990.

PÊGO FILHO, B.; CÂNDIDO JÚNIOR, J.; PEREIRA, F. Investimento e financiamento da infraestrutura no Brasil: 1990/2002. Brasília: IPEA, Texto para discussão no. 680, outubro de 1999.

PESSINI, J.; MACIEL, C. Modelos de Regulação e Políticas Públicas em Telecomunicações In. COUTINHO, L.; CASSIOLATO, J.; SILVA, A. (coord.). Telecomunicações, Globalização e Competitividade. 1995. 
PINHEIRO, A., GIAMBIAGI, F.; MOREIRA, M. O Brasil na década de 1990: uma transição bem-sucedida?. Texto de Discussão no. 91, BNDES, 2001.

PIRES, J.; GREMAUD, A. "Metas e Bases" e I Plano Nacional de Desenvolvimento - I PND (1970-1974) in. KON, A. (Org.) Planejamento Econômico no Brasil II, São Paulo, Editora Brasiliense, p. 41-67, 1999.

PIRES, J.; PICCININI, M. A economia brasileira nos anos 90: a regulação dos setores de infraestrutura no Brasil. BNDES. 1999. Disponível em: $<$ http://www.bndes.gov.br/SiteBNDES/export/sites/default/bndes_pt/Galerias/Arquivos/conhecimento/livro/eco90_07.pdf >. Acessado em 15.09.2010.

POSSAS, M., PONDÉ, J.; FAGUNDES, J. Regulação da Concorrência nos Setores de Infraestrutura no Brasil: elementos introdutórios para um quadro conceitual. Relatório de Pesquisa/IPEA, 1997, 40 págs. Disponível em: $<$ http://www.ie.ufrj.br/grc/pdfs/regulacao_da_concorrencia_nos_setores_de_infraestrutura_no_brasil.pdf $>$. Acessado em 12.08.2010.

PRADO JR., C. História econômica do Brasil. Editora Brasiliense. São Paulo, $45^{\mathrm{a}}$. reimpressão, 2002.

REGO, J.; MARQUES, R. (Org.) Economia Brasileira. Editora Saraiva. São Paulo, 2001.

REIS, C. Investimento Público e desenvolvimento econômico: análise aplicada ao Brasil entre 1950 e 2006, com base em uma perspectiva teórica keynesiana e estruturalista. (mimeo). 2008.

RIGOLON, F. O investimento em infraestrutura e a retomada do crescimento econômico sustentado. Revista Pesquisa Planejamento Econômico. Rio de Janeiro, 1998.

RODRIGUEZ, O. Teoria do subdesenvolvimento da CEPAL. Rio de Janeiro: Ed. Forense-Universitária, 1981.

. Regulação da infraestrutura: a experiência recente no Brasil. Nota Técnica AP/Depec no. 29, BNDES. Disponível em: <http://www. 
bndes.gov.br/SiteBNDES/export/sites/default/bndes_pt/Galerias/Arquivos/ conhecimento/revista/rev705.pdf $>$. Acessado em 22.02.2011.

ROZAS, P. América Latina: problemas y desafíos del financiamiento de la infraestructura. Revista Cepal 101 - p. 59-83. Agosto 2010.

SECRETARIA DE ASSUNTO ESTRATÉGICOS - PRESIDÊNCIA DA REPÚBLICA FEDERATIVA DO BRASIL. Apoio do BNDES à Infraestrutura, de set. 2010. Disponível em: $<$ http://www.sae.gov.br/enee/wp-content/ uploads/2010/06/Infraestrutura_MR4_BNDES_WagnerOliveira.pdf $>$.Acessado em: 24.03.2011.

SALGADO, L.; SEROA DA MOTTA, R. (Ed.) Marcos Regulatórios no Brasil: o que foi feito e o que falta fazer. IPEA. Rio de Janeiro, 2005. Disponível em: <http://www.ipea.gov.br/portal/images/stories/PDFs/livros/ marcosRegulatoriosNoBrasil-11.pdf $>$. Acessado em: 04.03.2011.

SARETTA, F. A Política Econômica no período 1954/1955. Algumas notas. $\mathrm{V}$ Encontro de Economistas da Língua Portuguesa. Recife. Novembro de 2003.

SICSÚ, J. Emprego, juros e câmbio: finanças globais e desemprego. Rio de Janeiro: Elsevier, 2007.

SIMONSEN, M. A inflação brasileira: lições e perspectivas. Revista de Economia Política, vol. 5, no. 4, outubro-dezembro. 1985. .; CYSNE, R. Macroeconomia - 4a . Ed. - São Paulo: Atlas, 2009.

TAVARES, M. Da substituição de importações ao capitalismo financeiro: ensaios sobre a economia brasileira. Editora Zahar, 6 ${ }^{\mathrm{a}}$. Edição. 1977.

; FIORI, J. (Des)ajuste global e modernização conservadora. Editora Paz e Terra, Rio de Janeiro, 1996. 
TUROLlA, F., PAIVA, A.; MONTEIRO, E. A internacionalização das empresas de infra-estrutura. III Simpósio Internacional de Administração e Marketing/ V Congresso de Administração da ESPM.

VALADARES DA SILVA, M. Política industrial e interesses empresariais: o II PND (1974-1979). V Congresso Brasileiro de Histórica Econômica, da Associação Brasileira de Pesquisadores em História Econômica (ABPHE). Caxambú, 2003.

VELASCO JR., L. A privatização no sistema BNDES. Documento histórico. Revista do BNDES 33, p. 307-382, junho, 2010.

VELOSO, F., VILLELA, A.; GIAMBIAGI, F. Determinantes do "Milagre" econômico brasileiro (1968/73): uma análise empírica. Revista Brasileira de Economia, v. 62, n. 2, p. 221-246, Abr-Jun. 2008.

VILLELA, A. Dos “anos dourados” de JK à crise não resolvida (1956-1963). In. GIAMBIAGI, F.; VILLELA, A. Economia brasileira contemporânea (1945-2004). Editora Campus, 2005.

; MACIEL, C. A regulação do setor de infraestrutura econômica: uma comparação internacional. IPEA - texto para discussão no. 684. Brasília. 1999.

\section{Anexo 1. Brasil: coeficientes de investimento total e em infraestrutura (\% PIB)}

\begin{tabular}{|c|c|c|}
\hline Período & FBKF & Investimentos em Infraestrutura \\
\hline $1970-79$ & 23,5 & 5,4 \\
\hline $1980-89$ & 22,2 & 3,6 \\
\hline $1990-99$ & 18,2 & 2,3 \\
\hline
\end{tabular}

Fonte: elaboração própria, com de dados de Bielschowsky (2002), IBGE e ABDIB. 